\title{
A study on the groundwater contamination by the agriculture fertilizer inputs and its spatial distribution pattern in the Zhangye basin, Northwest China
}

\author{
Aruna Bandara ${ }^{a}$ and Tomohiro Akiyama ${ }^{\text {b1 }}$ \\ ${ }^{a}$ Department of Town \& Country Planning, University of Moratuwa, Sri Lanka \\ ${ }^{\mathrm{b}}$ Graduate Program in Sustainability Science, Graduate School of Frontier Sciences, University of Tokyo, Tokyo, \\ Japan
}

\begin{abstract}
The Heihe River is one of the largest rivers in Gansu province in China, which originates from Qilian Mountains and terminates at Ejina Basin in Gobi desert. The river is the only water source of the region, which is highly dependent on agriculture-based economy. The recent changes of economic and environmental sectors have been affected the sustainable agricultural practices of the region. Those changes may give adverse impacts on water quality. In this context, this study focuses on the water quality of both shallow-groundwater and deep-groundwater in the middle reaches of the Heihe River basin, the main agricultural region of the basin. Total of 35 water samples are used for measure water quality, i.e $\mathrm{NO} 3-, \mathrm{NO} 2-, \mathrm{NH} 3$ and $\mathrm{pH}$. The water quality measurement results indicate two different spatial distribution patterns of chemical contamination respectively for shallow and deep ground water. This paper discusses the current spatial pattern of nitrogen contamination of the groundwater and its temporal change through the comparison with the past studies.
\end{abstract}

Keywords: The Heihe River basin, Groundwater quality, Chemical fertilizer, Groundwater recharge

\section{Introduction}

Groundwater pollution is a critical global problem because most dry and arid regions in the world are highly dependent on groundwater (Fang and Ding, 2009). The most frequently found pollutant in groundwater is nitrogen, which causes many health problems (Spalding and Exner, 1993). Higher concentration of Nitrogen in drinking water could affect the transport of oxygen in the blood, which cause methemoglobinemia for infants, while it also could cause childhood diabetes and stomach cancer ( Di and Cameron, 2002; Addiscott, 2004). The nitrogen concentration in groundwater could happen naturally or caused by human-related activities. But the concentration levels exceeding $3 \mathrm{mg} / 1 \mathrm{NO} 3-\mathrm{N}$ or 13 $\mathrm{mg} / \mathrm{l} \mathrm{NO} 3$ - are considered to be caused by human related activities. The WHO has set quality standards for drinking water, which indicates the maximum acceptable concentration of nitrate is $50 \mathrm{mg} / 1 \mathrm{NO} 3-(11.3 \mathrm{mg} / \mathrm{l} \mathrm{NO} 3$ - -N) (WHO, 2007).

Zhangye city, which is located in Gansu Province, Northwest of China, is mainly dependent on an agriculture-based economy. The recent rapid economic growth of China has resulted increasing demand of agricultural products, which motivates a rapid expansion of agricultural activities in Heihe River basin (Wang et.al, 2009). The groundwater in the Heihe River basin entirely depends on the river water, which is supplied by the southern Qilian Mountains. The ground water is the main water source for agriculture as well as for drinking purpose, similar to many other arid regions in the world. The intensive agro-production and the rapid extraction of groundwater lead to critical environmental problems in Zhangye area. The significant decline of groundwater level (Wang et.al, 2009) and increasing concentration of nitrogen level in groundwater (Chang and Wang, 2009) are two main environmental concerns in this context. The water quantity issue has gained a significant attention of scholars (Wang et.al, 2009; Chen et.al, 2005; Wang and Chen, 2000) and meanwhile the water quality issues are also addressed in different perspectives including its hydrochemical characteristics, nitrogen infiltration through agricultural activities, ground water recharge process and water quality etc (Wen et.al, 2007; Yang et.al, 2011; Chang and Wang, 2009; Qin, 2011). 
The groundwater pollution should be a critical concern not just because the point source pollution, but also its distribution by non-point source pollution. The water cycle is the most important factor in this regards, where groundwater table and its moments play an important role in distributing the pollutants. The studies done on the spatial distribution of nitrogen contamination of ground water, indicates that in 2004, the groundwater in the area of Zhangye city was highly contaminated (Fang and Ding, 2009). Further, according to the studies done by Yang et.al (2004) on the nitrogen accumulation in soil in Northwestern China, including Zhangye basin, it shows a correlation between the nitrogen contamination of soil and intensity of fertilizer application in agriculture over a long period (1982-2000). This is a possible cause for the high contamination of nitrogen in groundwater in Zhangye basin. Further, the over use of chemical fertilizer (Wang et.al, 2010) could be an important cause for this result.

After 2004 some paddy areas (northern part of Zhangye city) those were originally wetlands, were converted back to wetlands and in 2006, a sewerage treatment plant was established in the same area. Both those projects have a significant influence on water cycle. The wetlands have the capacity to purify the water and also the sewer treatment reduces the pollutant discharge to the natural environment.

The water quality issue in Zhangye region has been widely studied by many scholars but its temporal changes in spatial distribution are rarely discussed. The land use changes, specially the changes related to wetlands could have significant impacts on water quality fluctuations over time (Zhang, 2009). In this background, this paper discusses the changing pattern of groundwater quality with relating the groundwater recharge process and wetland related land use changes in Zhangye city area.

\section{Study Area}

The study area of this research is Zhangye Basin, which is centered by Zhangye city. The Zhangye Basin is located in middle reaches of the Heihe River Basin and it is the main cultivated area in the Heihe River Basin. The Zhangye Basin serves for nearly 1.3 million population and covers approximately 4 million hectares of land. Nearly $70 \%$ of the total area is used for agricultural activities. The region receives a low annual precipitation, $117 \mathrm{~mm}$, and most of the precipitation is concentrated during July-September period. The mean annual evaporation is as high as $2390 \mathrm{~mm}$. The main agricultural products are seed corn and vegetables. In 2005 , the total amount of nitrogen fertilizers applied on the maize fields was above $300 \mathrm{~kg}$ ha-1 year-1 (Yang and $\mathrm{Su}, 2010)$.
The hydrological setting of Zhangye basin is illustrated in Figure 2 (Fang et.al, 2009). The transect drawn from south to north; from Qilian mountains to Longshou mountains. In the southern part of the region, the aquifer is formed $300 \mathrm{~m}$ to $500 \mathrm{~m}$ depth by cobble and gravel while the northern part is formed with cobble, gravel, fine sand and clay in $100 \mathrm{~m}-200 \mathrm{~m}$ thickness. The fan fluvial deposits accumulated from Qilian Mountains forms an unconsolidated Quaternary sediments in a depth of $300 \mathrm{~m}-500 \mathrm{~m}$. The thickness of the groundwater table becomes shallow as it moves towards the downstream (north). (Fang et.al, 2009)

The paper mainly focuses on the adjacent area of the Zhangye city (Figure 3), which is attracted a dense agricultural activities and dense population.

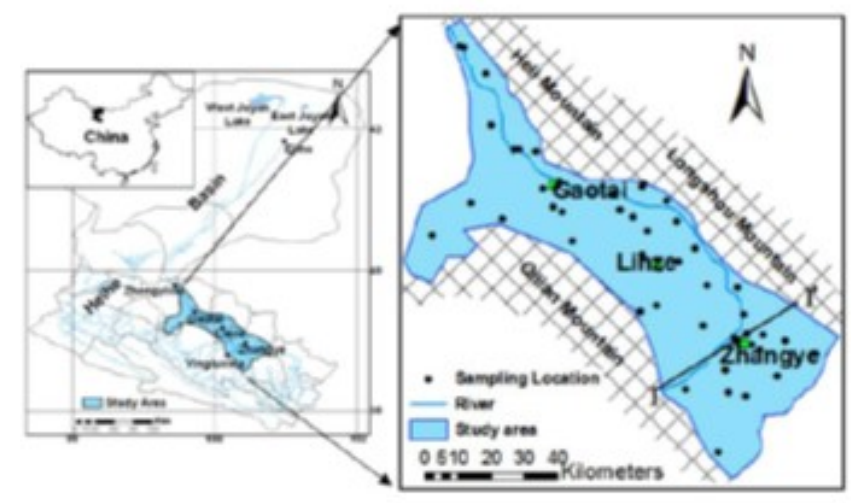

Figure 1: Framework Transect I-I' (Fang, et al., 2011)

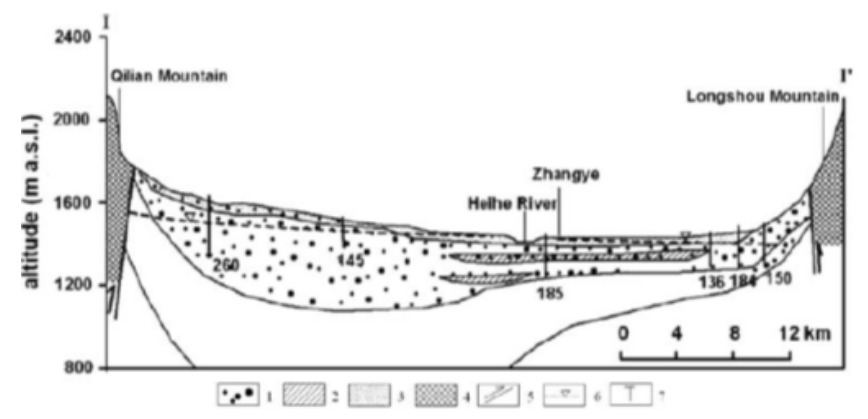

Figure 2: Hydrological cross section along transect I-I'. Legend: 1 Gravel, 2 clay, 3 sand, 4 base rock, 5 fault line, 6 groundwater table, 7 borehole and depth (Fang, et al., 2011)

\section{Materials and Method}

From the study area, 35 samples were collected from shallow and deep groundwater sources, between the period of September 2nd to 4th 2011. The samples were collected from the sources such as drinking water wells, observation wells and natural springs. The depths of the wells varied from less than $10 \mathrm{~m}$ to more than $150 \mathrm{~m}$.

The water quality parameters mainly focused on nitrogen contamination in the groundwater. The water samples were subjected to a quality measurement for nitrate nitrogen (NO3- -N) nitrite (NO2-), ammonia (NH3), electric conductivity (EC) and $\mathrm{pH}$. The EC and 
$\mathrm{pH}$ were measured on-site and others were measured within 12 hours and samples were stored in ice-box while transporting. For the measurements $\mathrm{HACH}$ DR890 Portable Colorimeter and Horiba D-55 pH/EC meter were used.

To register the sample location, a GPS receiver was used and the preparation of maps and the visual analysis were done using ArcGIS 9.3 software.

\section{Results}

The water quality measurement results in the area of Zhangye city for noted parameters are as follows (Table $1)$. From the summary of the sample analysis results, the NO3- -N levels of the groundwater, is highlighted. The maximum nitrate nitrogen (NO3- -N) level, which is recommended by the $\mathrm{WHO}$ is $11.3 \mathrm{mg} / \mathrm{l}$, has been exceeded by a higher margin $(19.6 \mathrm{mg} / \mathrm{l})$. Out of total 35 samples, 3 samples exceed this value $(19.6,13.5$ and 13.1).

Table 1: Water quality analysis results

\begin{tabular}{|l|l|l|l|l|l|}
\hline & $\mathbf{p H}$ & $\mathbf{E C}$ & $\mathbf{N O}^{3}-\mathbf{- N}$ & $\mathbf{N O}_{2^{-}}$ & $\mathbf{N H}_{\mathbf{3}}$ \\
\hline Mean & 7.87 & 93.05 & 5.17 & 0.018 & 0.08 \\
\hline St. Dev & 0.36 & 37.36 & 5.19 & 0.060 & 0.26 \\
\hline Min & 7.34 & 48.70 & 0.40 & 0.001 & 0.00 \\
\hline Max & 8.59 & 180.00 & 19.60 & 0.279 & 1.20 \\
\hline
\end{tabular}

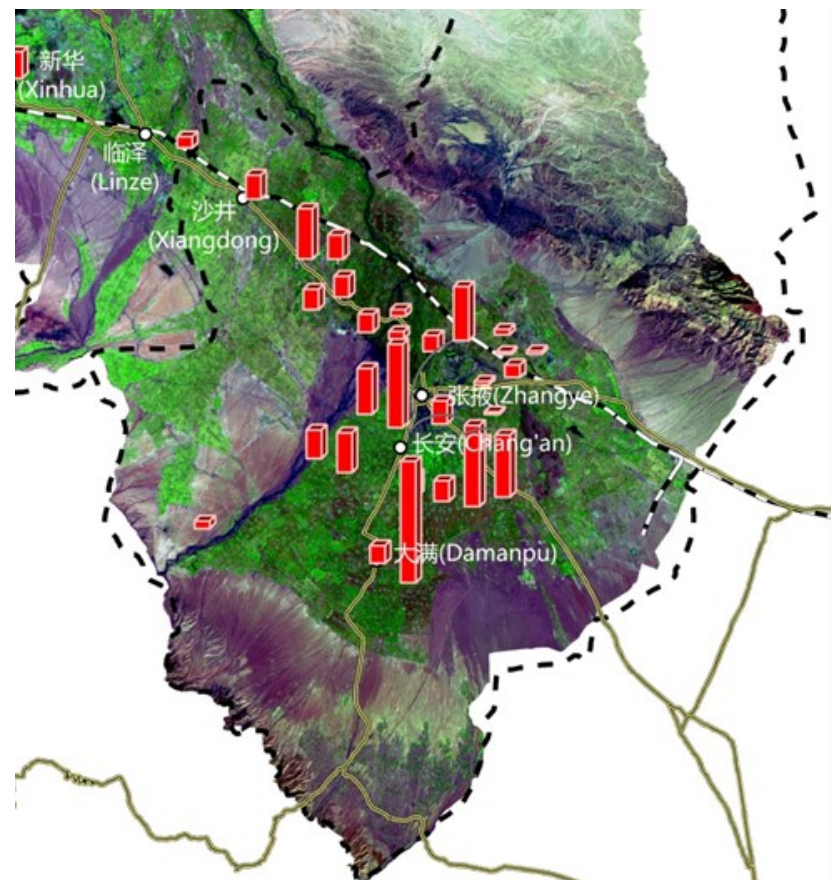

Figure 3: Sampling sites and spatial distribution of $\mathrm{NO}_{3}-\mathrm{N}$ concentration

\subsection{Discussion}

The spatial distribution of the NO3- -N contamination of groundwater highlights a trend. The groundwater in transect parallel to the river records declining pattern of contamination from south to north (Figure 4). As it illustrates in Figure 4, the NO3- -N contamination of the shallow groundwater along the transect parallel to the river, clearly declines as it moves downstream. As it shows in the Figure 4, the contamination level drops down as the depth of the groundwater table decreases.

This trend has resulted to record a low level of nitrogen contamination in the groundwater in the northern part of Zhangye city.

The decreasing trend of groundwater pollutants can be explained by the groundwater recharge process (Qin, 2011) which is reflected by the electric conductivity of the groundwater. As the irrigation network distributes river water for agricultural activities, the groundwater is recharged by the river water, which causes the declining trend of the shallow groundwater. However, the recharge rate of deep groundwater is not frequent as shallow groundwater, which results in accumulation of the pollutants as it flows to downstream.

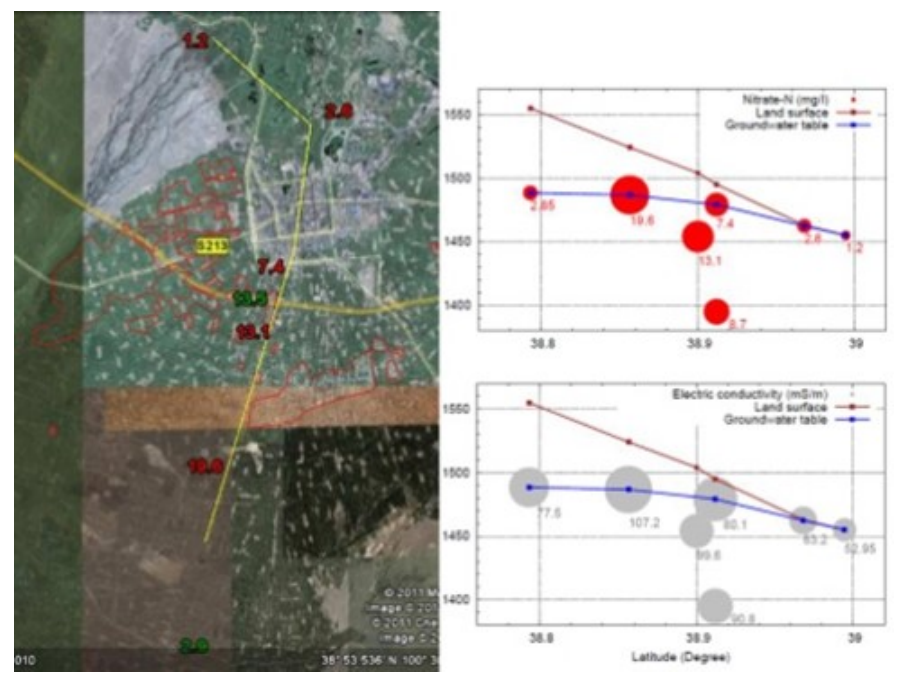

Figure 4: Transect I-I'

The spatial distribution pattern of the nitrogen contamination in ground water in this research has a significant difference from results of the same study done in 2004. Figure 5 illustrate the contour maps of nitrogen contamination of groundwater in Zhangye city region in 2004 and 2011. In 2004, the peak concentration has been reported in immediate northern part of Zhangye city (Fang et.al, 2009). The results in 2011 shows a drastic change and the contamination on the same area was found to be lowest in this study, while

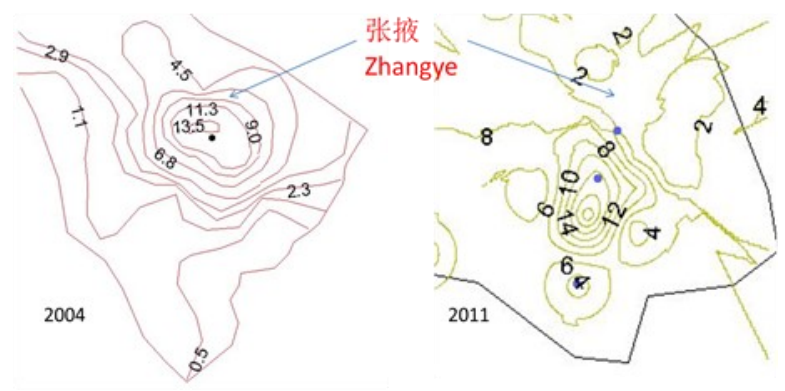

Figure 5: $\mathrm{NO}_{3}-\mathrm{N}$ contamination in groundwater in Zhangye city region; 2004 and 2011

Fang et.al, (2009) 
the contamination level in the southern area has increased (Figure 5).

The Northern area of the city has recorded less than 3 $\mathrm{mg} / 1 \mathrm{NO} 3-\mathrm{N}$ level in groundwater in 2011 and the same area was recorded as highly contaminated in 2004, nearly $9 \mathrm{mg} / \mathrm{l} \mathrm{NO} 3-\mathrm{N}$. Although the overall nitrogen contamination has increased in the region, it has been drastically dropped down in this specific region in a 7 years period.

During the period of 2004-2011, two major events have been recorded in the northern part of the Zhangye city region, namely, the conversion of paddy lands into wetlands under the project of "Construction of Water Saving Society" and introduction of the sewer treatment plant in 2006. The denitrification process taken place in wetlands is identified as an effective natural method for purify water (Zhang et.al, 2009) and the introduction of wetlands could be a causative factor for the above phenomenon. Inappropriate sewer disposal is also considered as a important causative factor for nitrogen increase in groundwater (Bishop, 1998) and the introduction of sewerage treatment plant also has a capability to impact on reducing the nitrogen contamination of the groundwater in this area.

\section{Conclusion}

Commercial agriculture is the spine of the Zhangye economy. Similarly, scarce water resource is a main determine factor for people in Zhangye. The conflict between these two factors is the major issue in this region. As it increases its production it has reached to its maximum carrying capacity. The distribution pattern of the NO3- $-\mathrm{N}$ contamination indicates that with high accumulation of NO3- $-\mathrm{N}$ in deep groundwater. The rate of NO3- -N intrusion exceeds the capacity of the natural groundwater purification process; i.e., groundwater recharge. It can assume that the recent trends of over application of chemical fertilizer has caused for this. In order to adapt to the situation, the trends show that more natural solutions such as introducing wetlands, could be effective. This argument is well supported by the correlation between the changes of the groundwater pollutant contamination and the environmental projects took place in the region. The sudden drop of the nitrogen contamination of the groundwater is highly possible to be caused by the conversion of the paddy fields into wetlands and introducing the sewer treatment in the region.

\section{References}

Addiscott T.M. and Benjamin N, 2004, 'Nitrate and human health', Soil Management and Use, Wiley, 20(2): 98-104.

Bishop P.K, et al, 1998, 'Impacts of Sewers on Groundwater Quality', Water and Environment Journal, Wiley, 12(3): 216-223.

Chang J. and Wang G, 2009, 'Major ions chemistry of groundwater in the arid region of Zhangye Basin, northwestern China', Environmental Earth Sciences, Springer, 39(3): 539-547.

Di H.J. and Cameron K.C, 2002, 'Nitrate leaching in temperate agroecosystems: sources, factors and mitigating strategies', Nutrient Cycling in Agroecosystems, Springer, 64(3): 237-256.

Fang J. and Ding Y, 2009, 'Assessment of groundwater contamination by $\mathrm{NO}_{3}$ ' using geographical information system in the Zhangye Basin, Northwest China', Environmental Earth Sciences, Springer, 60(4): 809-816.

Qin D. et.al, 2011, 'Assessing impact of irrigation water on groundwater recharge and quality in arid environment using CFCs, tritium and stable isotopes, in the Zhangye Basin, Northwest China', Journal of Hydrology, Elsevier, 405: 194208.

Spalding R.F and Exner M.E, 1993, 'Occurrence of nitrate in groundwater- a review', Journal of Environmental Quality, ASA, 22(2): 392-402.

Wang G. and Chen G, 2000, 'The characteristics of water resources and the changes of the hydrological process and environment in the arid zone of northwest China', Environmental Geology, Springer, 39(7): 783-790.

Wang Q, et.al, 2010, 'Effects of irrigation and nitrogen application rates on nitrate nitrogen distribution and fertilizer nitrogen loss, wheat yield and nitrogen uptake on a recently reclaimed sandy farmland', Plant Soil, Springer, 337(1-2): 325-339.

Wen X.H, Wu, Y.Q., Wu, J 2007, 'Hydrochemical characteristics of groundwater in the Zhangye Basin', Northwestern China, Environmental Geology, Springer, 55(8): 1713-1724.

Yang R. and Su Y, 2010, Groundwater nitrate contamination in an agroecosystem in Zhangye Oasis, Northwest China, Environmental Earth Sciences, Springer 61(1): 123-129. 
Yang S, et.al, Fengmin L., Malhi, S.S., Wang, P., Suo, D., Wang, J. 2004, 'Long-Term Fertilization Effects on Crop Yield and Nitrate Nitrogen Accumulation in Soil in Northwestern China', Agronomy Journal, American Society of Agronomy, 96(4): 1039-1049.

Yang S. Wang, P., Suo, D., Malhi, S.S., Chen,Y., Guo, Y.J., Sheng-Zhe E., Zhang,D., 2011, 'Short-Term Irrigation Level Effects on Residual Nitrate in Soil Profile and N Balance from Long-Term Manure and Fertilizer Applications in the Arid Areas of Northwest China', Communications in Soil Science and Plant Analysis, Taylor \& Francis, 42 (7): 790-802.Zhang D, et.al, 2009, 'Constructed wetlands in China', Ecological Engineering, Elsevier, 35(10): 13671378. 